\title{
Manejo de n-acetilcisteina en amenaza de parto pretérmino.
}

Management of n-acetylcysteine in threatened preterm delivery.

Maritza Paulina Castillo Vásquez. ${ }^{1}$, María de los Ángeles Sánchez Tapia. ${ }^{2}$, Marco Leopoldo Medina Sarmiento. ${ }^{3}$

Recibido: 14-03-2017 / Revisado: 08-05-2017 Aceptado: 10-06-2018/ Publicado: 01-07-2018

\begin{abstract}
.
DOI: https://doi.org/10.33262/cienciadigital.v2i3.171
\end{abstract}

The objective of this study is to select a material that replaces and improves the performance shown by the steel AISI 1030, used for the manufacture of the blades of tillage of the YTO DF 15I tractors of Chinese origin, intended for work in the soils of region's center of Ecuador. AISI 1030 steel presents a low reliability for this type of applications. The material selection procedure is based on the method proposed by ASHBY. The design requirements of the blades, consider restrictions for the material, such as: minimum specified yield strength, specified hardness, feasibility of being forged and feasibility of being thermally welded. In addition, the objective is to maximize the fracture tenacity and, of course, minimize the price of the material; to achieve that, a material index is used to identify the best performing materials, which optimizes the selection. With the help of a material selection software, it was possible to debug all available information, and it turned out that the low alloy steel AISI 4135, hardened and tempered, could be a strong candidate to replace the AISI 1030 steel, since, apart from to comply with all the restrictions required for the design, it also has the highest value of fracture/price tenacity ratio $\left(K_{I c} / P=200\right)$.

Keywords: Preterm birth, $\mathrm{N}$ - acetylcysteine, urinary tract infection, vaginosis.

\section{Resumen.}

\footnotetext{
${ }^{1}$ Doctor en Medicina y Cirugía, Especialista en Ginecología y Obstetricia, Cuenca, Ecuador, mpaulyndoc@hotmail.com

${ }^{2}$ Doctor en Medicina y Cirugía, Especialista en Ginecología y Obstetricia, Cuenca, Ecuador, marjha123@gmail.com

${ }^{3}$ Doctor en Medicina y Cirugía, Especialista en Ginecología y Obstetricia, Cuenca, Ecuador, arcomedsar@hotmail.es
} 
La amenaza de parto pretérmino, es causa de morbilidad-mortalidad neonatal, entre la 22 y 37 semanas de gestación, afecta al 10\%-15\% de los nacimientos, según la OMS, el Ecuador está dentro de los 10 países con las mayores tasas de nacimientos prematuros por cada 100 nacimientos en relación 5:1. En países de bajos ingresos, las causas de nacimientos prematuros incluye stress, traumatismos, patología cervical, alta incidencia de infección de vías urinarias y vaginosis; los objetivos del trabajo: determinar la eficacia del uso de $\mathrm{N}$ - acetilcisteina como coadyuvante en el tratamiento de amenaza de parto pretérmino causada por infección de vías urinarias y/o vaginosis; sus efectos en la prolongación del embarazo hasta la semana 37 y evaluar el porcentaje de reingreso hospitalario. El estudio se realizó en el servicio de Gineco-Obstetricia del Hospital General Isidro Ayora de Loja, enero-abril 2014. Estudio de tipo experimental aleatorizado, controlado con placebo, en 63 gestantes con amenaza de parto pretérmino que cumplieron los criterios de inclusión y exclusión. Los resultados: N-acetilcisteina, prolongó el periodo de gestación, alcanzando una media de 37,19 semanas; en el grupo placebo la media fue de 35,78 semanas; el reingreso hospitalario en el grupo $\mathrm{N}$-acetilcisteina $28.1 \%$, en el grupo placebo 45,2\%. El uso de $\mathrm{N}$-acetilcisteina es efectivo en la prolongación del embarazo en amenaza de parto pretérmino por infección de vías urinarias-vaginosis bacteriana, reduce el reingreso hospitalario en un $72 \%$. Se recomienda incrementar el uso de $\mathrm{N}$-acetilcisteina como coadyuvante en el tratamiento de amenaza de parto pretérmino.

Palabras Claves: Amenaza Parto pre término, Infección de Vías urinarias, Nacetilcisteina, Vaginosis.

\section{Introducción.}

En muchas ocasiones, el embarazo se ve amenazado por diversas patologías que pueden elevar la morbi-mortalidad materna y neonatal. Una de las principales complicaciones es consecuencia del parto pretérmino, lo que constituye un problema de Salud Pública. Su incidencia varía entre 5 y $12 \%$ en las regiones desarrolladas del mundo, pero puede ser de hasta $40 \%$ en las regiones más pobres. En nuestro país, entre el 8 y $9 \%$ de los nacimientos están representados por los pre-términos, y estos constituyen el $75 \%$ de mortalidad perinatal; su etiología así como su manejo sigue siendo causa de discusión. (Organizacion Mundial de la Salud, 12 de junio del 2012.), (Sociedad Española de Ginecología y Obstericia, 29/06/2011).

Se ha considerado, que la infección de vías urinarias, es después de la ruptura prematura de membranas, la patología más frecuente asociada en el parto pretérmino, su incidencia fluctúa entre 3 y 12\%. El 20\% de las embarazadas presentan una infección de vías urinarias bajas en el curso de la gestación. (Ministerio de Salud Pública del Ecuador, 2009). 
Así mismo la vaginosis bacteriana, origina una de las infecciones vaginales más comunes, que en el embarazo puede colonizar la placenta y provocar la inflamación del feto. Esa respuesta por parte del feto podría desembocar en un parto pretérmino, lesiones y complicaciones poniendo en peligro su vida.

La prevalencia informada en embarazadas con vaginosis bacteriana oscila entre el $14 \%$ y el $21 \%$, provocando un riesgo potencial de rotura prematura de membranas, amenaza de parto prematuro, e inicio del trabajo de parto entre mujeres portadoras de vaginosis bacteriana. (Organizacion Mundial de la Salud, 12 de junio del 2012.) (Ministerio de Salud Pública del Ecuador, 2009)

Los antibióticos actualmente utilizados para tratar la infección de vías urinarias y la vaginosis bacteriana en el embarazo son adecuados, sin embargo existe una elevada tasa de recidivas, por la respuesta antiinflamatoria e inmunológica de cada paciente, sumada a la resistencia bacteriana.

Actualmente se han realizado nuevas investigaciones, con el fin de mejorar las respuestas a tratamientos médicos ya establecidos para este tipo de infecciones.

Dentro de la nueva tendencia farmacológica existen medicamentos que han sido estudiados ampliamente por sus múltiples propiedades, entre ellos la $\mathrm{N}$-acetilcisteina, poderoso antioxidante, con acciones antiinflamatorias, antioxidativas y antiinfecciosas, entre otras. ( International journal of gynecology and obstetrics, 2009).

La N-acetilcisteina, estimula en el organismo la síntesis de glutatión, aminoácido que promueve la desintoxicación, mejora la respuesta antiinflamatoria e inmunológica, y actúa directamente como un eliminador de radicales libres. ( International journal of gynecology and obstetrics, 2009).

Recientes estudios han confirmado la eficacia de la N- acetilcisteina en la descomposición y reducción del número de formas vitales de bacterias. Además, se afirma que la actividad de $\mathrm{N}$-acetilcisteina en asociación con antibióticos posee un efecto sinérgico antibacteriano, es decir, aumenta los efectos antibacterianos alcanzados por cada sustancia cuando se administra de forma individual. (Heba Ahmed Mohamed, Minia University, 2013) (Lo.Li. Pharma S.R.L., 2012)

Por tal razón se ha considerado a la $\mathrm{N}$-acetilcisteina como una nueva alternativa de tratamiento coadyuvante en la amenaza de parto pretérmino causado por: infección de vías urinarias y/o vaginosis.

Esta nueva opción de tratamiento, sumada al tratamiento antibiótico y tocolítico, actualmente ofrecen una mayor posibilidad de prevención del parto pretérmino, y así, 
alcanzar una gestación hasta la semana 37, mejorar el flujo de oxigeno materno fetal, y, evitar graves e irreversibles secuelas neurológicas en los recién nacidos.

Es entonces, eficaz la $\mathrm{N}$ - acetilcisteina como tratamiento coadyuvante en la amenaza de parto pretérmino causada por infección de vías urinarias y/o vaginosis? Ayuda a la prolongación del embarazo hasta la semana 37? Disminuye el porcentaje de reingreso hospitalario?

\section{Materiales y métodos.}

Estudio cuasi experimental aleatorizado, controlado con placebo. El universo: constituido por el total de gestantes, con diagnóstico de amenaza de parto pretérmino, que ingresaron al servicio de Ginecología y Obstetricia del Hospital General Isidro Ayora de Loja, en el periodo enero-abril 2014; la muestra la constituyeron 63 pacientes con diagnóstico de amenaza de parto pretérmino, causada por infección de vías urinarias y/o vaginosis bacteriana, que cumplieron con los criterios de inclusión y exclusión.

\section{Criterios de inclusión:}

- Mujeres entre la semana 22 y 32 de gestación confirmado por las primeras ecografías.

- Pacientes con al menos 3 contracciones en 30 minutos, con dilatación menor a $3 \mathrm{~cm}$.

- Pacientes en amenaza de parto pretérmino, con Urocultivo y EMO positivo para infección de vías urinarias.

- Pacientes en amenaza de parto pretérmino, con examen de secreción vaginal positivo para vaginosis bacteriana.

\section{Criterios de exclusión:}

- Fechas menstruales irregulares y / o inciertas.

- Pacientes con trabajo de parto.

- Pacientes con ruptura de membranas

Se identificaron a las pacientes que ingresaron al departamento de Ginecología Obstetricia con diagnóstico de Amenaza de parto pretérmino más infección de vías urinarias y/o vaginosis bacteriana y se dividió a las pacientes en 2 grupos.

Grupo 1: pacientes que cumplieron con criterios de inclusión y se aleatorizaron para recibir $\mathrm{N}$-acetil cisteína. Grupo 2: pacientes que cumplieron con criterios de inclusión y se aleatorizaron para recibir placebo.

Cada grupo recibió a más del tratamiento (tocolítico a base de Nifedipino, y antibiótico terapia según el diagnóstico), una dosis diaria de 0,6 g de $\mathrm{N}$-acetilcisteina (grupo 1) y una cápsula de complejo B diaria como placebo (grupo 2), este tratamiento coadyuvante fue administrado durante 10 días. 
Las pacientes fueron monitorizadas durante toda su estancia hospitalaria, los controles posteriores al egreso fueron realizados por emergencia y, consulta externa. Se registró a las pacientes que reingresaron al establecimiento de salud, por recidiva del cuadro clínico, o labor de parto. Posteriormente se verificó el número de pacientes que alcanzaron las 37 semanas de gestación y se realizaron comparaciones entre los dos grupos. Los datos fueron analizados en el paquete estadístico SPSS, el análisis de correlación de las variables se la realizó a través de diferencias descriptivas utilizando ANOVA para el análisis de la varianza como prueba de significancia estadística.

\section{Resultados.}

Tabla 1. Diagnóstico Inicial de Ingreso, de las pacientes con Amenaza de Parto Pretérmino causada por: Infección de vías urinarias y/o Vaginosis.

\begin{tabular}{lcccc}
\hline \multirow{2}{*}{ DIAGNÓSTICO INICIAL } & \multicolumn{2}{c}{ N-ACETILCISTEINA } & \multicolumn{2}{c}{ PLACEBO } \\
& $\mathbf{F x}$ & $\mathbf{\%}$ & $\mathbf{f x}$ & $\boldsymbol{\%}$ \\
\hline APP+IVU & 13 & $20,60 \%$ & 9 & $14,40 \%$ \\
APP + VAGINOSIS & 5 & $7.9 \%$ & 6 & $9,50 \%$ \\
APP + IVU + VAGINOSIS & 14 & $22,20 \%$ & 16 & $25,40 \%$ \\
TOTAL & 32 & $50,70 \%$ & 31 & $49,30 \%$ \\
\hline
\end{tabular}

Fuente: Historias clínicas/Hoja de recolección de datos

Elaboración: Dra. Maritza Castillo, Dra. María de los Ángeles Sánchez Tapia

Del grupo con $\mathrm{N}$-acetilcisteína el 22,2\% $(\mathrm{n}=14)$ presentaron Amenaza de Parto Pretérmino más Infección de Vías Urinarias y Vaginosis. Del grupo placebo el 25,4\% $(\mathrm{n}=16)$ presentaron Amenaza de Parto Prematuro más Infección de Vías Urinarias y Vaginosis.

Tabla 2. Promedio de edad gestacional alcanzada luego del tratamiento, en las pacientes con amenaza de parto pretérmino

\begin{tabular}{lcccccc}
\hline $\begin{array}{l}\text { TRATAMIENTO } \\
\text { COADYUVANTE }\end{array}$ & Media & Fx & Desv. & $\begin{array}{c}\text { E.Gestac. } \\
\text { Mínima }\end{array}$ & $\begin{array}{c}\text { E.Gestac. } \\
\text { Máxima }\end{array}$ & Rango \\
\hline N-ACETILCISTEINA & 37,1 & 32 & 1,2 & 35,2 & 39,5 & 4,3 \\
PLACEBO & 35,7 & 31 & 2,1 & 25,5 & 38,5 & 13 \\
TOTAL & 36,5 & 63 & 1,8 & 25,5 & 39,5 & 14 \\
\hline
\end{tabular}

Fuente: Historias clínicas/Hoja de recolección de datos

Elaboración: Dra. Maritza Castillo, Dra. María de los Ángeles Sánchez Tapia ANOVA: .003

El tratamiento con $\mathrm{N}$-acetilcisteina prolonga el periodo de gestación: la media de gestación al momento del parto fue de 37.1 semanas. 
Tabla 3. Edad gestacional alcanzada luego del tratamiento, en las pacientes con amenaza de parto pretérmino

\begin{tabular}{lllllccc}
\hline \multirow{2}{*}{ DIAGNOSTICO } & \multicolumn{3}{c}{ NAC- . } & \multicolumn{3}{c}{ PLACEBO- E.GESTACIONAL } \\
\cline { 2 - 7 } & Fx & Media & Desv. & Fx & Media & Desv. \\
\hline APP + IVU & 13 & 37 & 1,3 & 9 & 35,3 & 3,8 \\
APP + VAGINOSIS & 5 & 36,7 & 1,4 & 6 & 36,1 & 0,6 \\
\hline
\end{tabular}

Fuente: Historias clínicas/Hoja de recolección de datos

Elaboración: Dra. Maritza Castillo, Dra. María de los Ángeles Sánchez Tapia

La media alcanzada es similar en las dos patologías.

Tabla 4. Reingreso hospitalario después del tratamiento en las pacientes con amenaza de parto pretérmino y/o vaginosis.

\begin{tabular}{lllll}
\hline \multirow{2}{*}{ REINGRESO HOSPITALARIO } & \multicolumn{2}{c}{$\mathbf{N}$-ACETILCISTEINA } & \multicolumn{2}{c}{ PLACEBO } \\
\cline { 2 - 6 } & $\mathbf{F x}$ & $\mathbf{\%}$ & $\mathbf{F x}$ & $\mathbf{\%}$ \\
\hline NO & 23 & $71.9 \%$ & 17 & $54.8 \%$ \\
SI & 9 & $28.1 \%$ & 14 & $45.2 \%$ \\
Total & 32 & $100 \%$ & 31 & $100 \%$ \\
\hline
\end{tabular}

Fuente: Historias clínicas/Hoja de recolección de datos

Elaboración: Dra. Maritza Castillo, Dra. María de los Ángeles Sánchez Tapia

El reingreso hospitalario de pacientes con tratamiento $\mathrm{N}$-acetilcisteina $28.1 \% \quad(\mathrm{n}=9)$ es menor al reingreso de pacientes que recibieron placebo que es de 45,2\%. $(n=14)$

\section{Discusión.}

El rango de edad promedio comprendido entre 15 y 25 años es el más frecuente entre las 63 pacientes del grupo $\mathrm{N}$-acetilcisteina y Placebo, siendo la Amenaza de parto pretérmino causada por infección de vías urinarias y vaginosis el diagnóstico más frecuente. Un estudio similar realizado en el 2007, en el centro de salud de la mujer de la Universidad de Assiut, Egipto, tomó en cuenta solo casos de pacientes con amenaza de parto pretérmino causada por vaginosis, donde la media de edad de sus pacientes fue de 26.5 años, sin tomar en cuenta la influencia de la edad de las pacientes en los resultados obtenidos.

En cuanto a edad gestacional, tanto el grupo $\mathrm{N}$ - acetilcisteina como placebo estuvieron conformados en su mayoría por pacientes entre 30 y 32 semanas 
Un menor número de pacientes. El promedio de edad gestacional de todo el grupo de estudio fue de 29.3 semanas, estas variables no interfirieron en los resultados obtenidos, puesto que los dos grupos son homogéneos.

El estudio realizado con $\mathrm{N}$ - acetilcisteina, en el Centro de Salud de la Mujer de la Universidad de Assiut, Egipto; entre enero y diciembre de 2007, realizado por Ahmed Y. Shahin, Ibrahim MA Hassanin, y cols, tomó en cuento solo casos de amenaza de parto pre término causada por vaginosis, la media de edad gestacional de sus pacientes fue de 17.4 semanas, puesto que, en el estudio se incluyeron casos de amenaza de aborto y amenaza de parto prematuro. ( International journal of gynecology and obstetrics, 2009)

Referente al diagnóstico inicial cabe destacar que la infección de vías urinarias (35\%) predominó sobre la vaginosis bacteriana (17.4\%) como causa de Amenaza de parto pretérmino. Sin embargo la vaginosis bacteriana más la infección de vías urinarias en los dos grupos de estudio comparten el mayor porcentaje (47.6\%). Lo que demuestra que las infecciones vaginales van asociadas en su mayoría a infecciones de vías urinarias como causa de amenaza de parto pretérmino.

La muestra fue cuasi simil en los dos grupos, no existió taza de abandono al tratamiento en ninguno de los dos casos, a diferencia del trabajo realizado en el Centro de Salud de la Mujer de la Universidad de Assiut, Egipto; entre enero y diciembre de 2007, por: Ahmed Y. Shahin, Ibrahim MA Hassanin, y cols, donde la tasa de abandono fue del $11.4 \%$ debido a los efectos secundarios de la droga. Los efectos secundarios reportados a la Nacetilcisteina, fueron nausea y vómito, probablemente asociados a la edad gestacional media (17 semanas) al inicio del estudio. (Effect of oral $\mathrm{N}$-acetyl cysteine on recurrent preterm labor following treatment for bacterial vaginosis).

El objetivo de esta investigación, valorar los efectos de $\mathrm{N}$-acetilcisteina en la prolongación del embarazo hasta la semana 37. Efectivamente el periodo de gestación en las pacientes que recibieron NAC, la media de gestación al momento del parto fue de 37.1 semanas. En tanto que, en quienes recibieron placebo, la media de gestación fue menor, de 35.7 semanas. Estos resultados son similares a los obtenidos en el ensayo realizado en el Centro de Salud de la Mujer de la Universidad de Assiut, Egipto; 2007, por Ahmed Y. Shahin, Ibrahim MA Hassanin, y cols, en donde la edad gestacional al momento del parto fue significativamente mayor en las pacientes que recibieron $\mathrm{N}$-acetilcisteina, 37.4 semanas; a diferencia del grupo que recibió placebo 34.1 semanas.

Actualmente existen varios estudios donde se demuestran los beneficios de la $\mathrm{N}$ acetilcisteina. En cuanto a embarazo y amenaza de parto pre término, estos estudios se han realizado en pacientes con vaginosis bacteriana, obteniéndose grandes resultados como los descritos anteriormente; sin embargo, a pesar de no contar con estudios que demuestren los 
beneficios del uso de $\mathrm{N}$-acetilcisteina en amenaza de parto pretérmino causada por infección de vías urinarias, los resultados obtenidos en la presente investigación son satisfactorios, puesto que se demostró la efectividad del NAC tanto en pacientes con Amenaza de parto pretérmino causado por infección de vías urinarias como en vaginosis bacteriana; prolongando la edad gestacional hasta la semana 37.0 en Amenaza de parto pretérmino causada por infección de vías urinarias y 36.7 semanas en Amenaza de parto pretérmino causada por vaginosis bacteriana.

En cuanto al reingreso hospitalario de pacientes con tratamiento de $\mathrm{N}$-acetilcisteina fue de $28.1 \%$, menor al reingreso de pacientes que recibieron tratamiento con placebo que fue de $45,2 \%$, destacando así que no solo mejora la adherencia al tratamiento antibiótico y tocolítico, sino que también mejora las condiciones futuras de la paciente gestantes. Cifras similares se encontraron en el estudio realizado en el Centro de Salud de la Mujer de la Universidad de Assiut, Egipto; entre enero y diciembre de 2007, por: Ahmed Y. Shahin, Ibrahim MA Hassanin, y cols.

\section{Conclusiones.}

- N-acetilcisteina, prolongó el periodo de grávido a una edad gestacional promedio de 37,1 semanas, en relación a las pacientes del grupo placebo.

- El reingreso hospitalario en las pacientes del grupo N-acetilcisteina fue porcentualmente menor relación 1:2 en relación al grupo placebo.

- El uso de $\mathrm{N}$-acetilcisteina es efectivo coadyuvante en la prolongación del embarazo en amenaza de parto pretérmino asociada tanto a infección de vías urinarias como a vaginosis

\section{Agradecimiento}

Al servicio de Ginecología y Obstetricia del Hospital General Isidro Ayora de Loja

\section{Referencias bibliográficas.}

International journal of gynecology and obstetrics. (2009). Effect of oral N-acetyl cysteine on recurrent preterm labor following treatment for bacterial vaginosis. Retrieved from www.elsevieier.com/locate/ijgo

Heba Ahmed Mohamed, Minia University. (2013). Role of N-Acetylcysteine in Treatment of Bacterial Vaginosis. Retrieved from https://clinicaltrials.gov/ct2/show/NCT01841411?term=bacterial+vaginosis\&rank= 13 
Lo.Li. Pharma S.R.L. (2012, 12 27). N-acetyl cysteine and composition thereof for use in the treatment of vaginal pathologies . Retrieved from http://www.google.com/patents/wo2012175659a1?cl=en

Ministerio de Salud Pública del Ecuador. (2009). Infección de Vías Urinarias. Protocolos de Atención Integral.

Organizacion Mundial de la Salud. (12 de junio del 2012.). Disponible en:. Perfil de Salud de país. Ecuador. Indicadores demográficos. . Retrieved from http://www.paho.org/spanish/sha/prflecu.htm.

Sociedad Española de Ginecología y Obstericia. (29/06/2011). Protocolos en Asistencia en Obstetricia. Elsevier. 
Para citar el artículo indexado.

Castillo M., Sánchez M. \& Medina M. (2018). Manejo de n-acetilcisteina en amenaza de parto pretérmino. Revista electrónica Ciencia Digital 2(3), 493-502. Recuperado desde: http://cienciadigital.org/revistacienciadigital2/index.php/CienciaDigital/article/view/171/15 $\underline{1}$

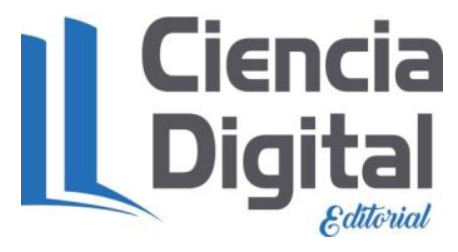

El artículo que se publica es de exclusiva responsabilidad de los autores y no necesariamente reflejan el pensamiento de la Revista Ciencia Digital.

El articulo queda en propiedad de la revista y, por tanto, su publicación parcial y/o total en otro medio tiene que ser autorizado por el director de la Revista Ciencia Digital.
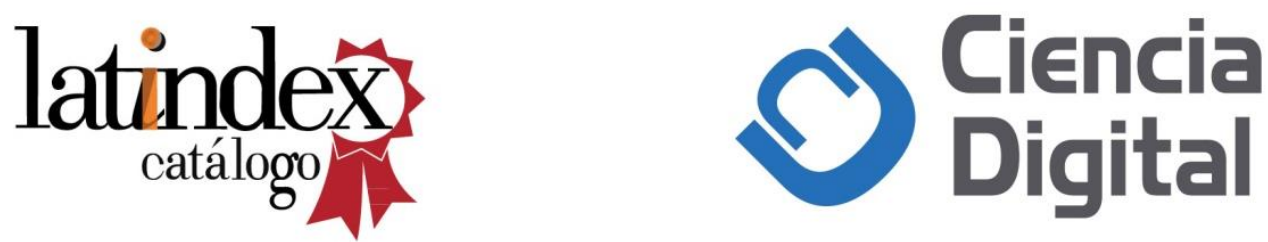